Case Report

\title{
Time Course in Ocular Blood Flow and Pulse Waveform in a Case of Ocular Ischemic Syndrome with Intraocular Pressure Fluctuation
}

\author{
Ryo Yamazaki, Ryuya Hashimoto *, Hidetaka Masahara ${ }^{\mathbb{D}}$, Masashi Sakamoto \\ and Takatoshi Maeno \\ Department of Ophthalmology, Toho University Sakura Medical Center, 564-1 Shimoshizu, Sakura 285-8741, Japan; \\ ryou.yamazaki@med.toho-u.ac.jp (R.Y.); hidetaka.masahara@med.toho-u.ac.jp (H.M.); \\ masashi.sakamoto@med.toho-u.ac.jp (M.S.); tmaeno@sakura.med.toho-u.ac.jp (T.M.) \\ * Correspondence: ryuuya.hashimoto@med.toho-u.ac.jp; Tel.: +81-43-462-8811; Fax: +81-43-462-8820
}

Received: 9 April 2020; Accepted: 4 June 2020; Published: 10 June 2020

check for updates

\begin{abstract}
We report on a 70-year-old Japanese man with complaints of worsening left visual acuity who was diagnosed with ocular ischemic syndrome (OIS) associated with internal carotid artery (ICA) stenosis. A gonioscopy examination showed rubeosis iridis and elevated intraocular pressure (IOP) in the left eye $(50 \mathrm{mmHg})$ at the baseline visit. The optic nerve head $(\mathrm{ONH})$ and choroidal blood flow measured by laser speckle flowgraphy (LSFG) was impaired in the left eye compared with that in the right eye. Additionally, the blowout score (BOS), which indicates the variation of the mean blur rate (MBR) during systolic and diastolic periods, was decreased in the left eye. After treatment with an injection of bevacizumab and administration of Rho-associated kinase-inhibitor ripasudil eye drops, both ocular blood flow and BOS in each vascular bed gradually increased along with IOP reduction. The visual acuity also improved. The current case demonstrated increased blood flow and decreased fluctuation of blood flow in the $\mathrm{ONH}$ and choroid before and after the treatment in OIS with rubeosis iridis. The LSFG technique is useful to non-invasively assess the ocular circulation and pulse waveform in OIS.
\end{abstract}

Keywords: ocular ischemic syndrome; internal carotid artery stenosis; rubeosis iridis; ocular blood flow; pulse waveform; optic nerve head; choroid; laser speckle flowgraphy

\section{Introduction}

Ocular ischemic syndrome (OIS) is caused by chronic ocular hypoperfusion associated with stenosis of the internal carotid artery (ICA) or the common carotid artery [1]. ICA stenosis strongly affects both retinal and choroidal blood circulation. This is due to the fact that the central retinal artery and the short posterior ciliary artery comes from the ICA [2,3].

OIS is related to poor vision and visual field loss at the time of diagnosis, leading to permanent visual loss [4,5]. Once rubeosis iridis occurs, the already reduced blood flow can be easily disturbed by a higher ocular pressure, which contributes to a worse prognosis [4]. Hayreh et al. reported that carotid artery disease could induce ocular arterial occlusive disease as a result of embolism and hemodynamic disturbance [6]. Although fluorescein and indocyanine green angiography (FA and ICGA) are very useful tests to assess retinal and choroidal circulation in ocular arterial occlusive diseases [2,7], it is not always feasible to perform FA and ICGA due to an adverse reaction [8,9]. Therefore, it is very important to evaluate ocular blood flow in eyes with OIS associated with ICA stenosis using the non-invasive method.

Laser speckle flowgraphy (LSFG-NAVI ${ }^{\circledR}$, Softcare Co. Ltd., Fukuoka, Japan) is a non-invasive quantitative method; it is very useful for measuring the $\mathrm{ONH}[10,11]$, retinal $[12,13]$, and choroidal 
blood flow [14,15], based on the changes in the speckle pattern of the laser light reflected from the fundus of the eye (mean blur rate, MBR which is the parameter of blood flow speed) [16]. In addition to MBR, LSFG can analyze the pulse waveforms. The blowout score (BOS) is one of these parameters; it is considered an index of the blood flow that is maintained between heartbeats and is calculated as the difference between the maximum and the minimum MBR as well as the average MBR. High BOS indicates a high constancy of blood flow during the cardiac cycle [16].

The previous study that used LSFG demonstrated that MBR in the ONH and choroid in the affected eye significantly decreased compared with that in the fellow eye in OIS [17]. However, to the best of our knowledge, the time course of the optic nerve head, choroidal blood flow, and pulse waveform using LSFG in OIS with rubeosis iridis is yet to be investigated. Herein, we present a case of OIS associated with ICA stenosis after the treatment in which LSFG was used.

\section{Case Presentation}

A 70-year-old Japanese male presented at the first visit with complaints of worsening visual acuity in his left eye. Two weeks before his first visit, he experienced blurred vision and orbital pain. He visited the department of ophthalmology at a local hospital where it was determined that he had higher intraocular pressure (IOP) and rubeosis iridis in the left eye.

He was referred to Toho University Sakura Medical Center in Sakura, Japan (referred to hereafter as "our hospital") on the next day with the main complaint of worsening visual acuity and orbital pain in the left eye. He had a history of type 2 diabetes, hyperlipidemia, and hypertension without any treatment. At the baseline visit to our hospital, the patient's decimal best-corrected visual acuity (BCVA) in the left and right eyes were 0.4 and 1.0, respectively. The IOP in the left and right eyes were $50 \mathrm{mmHg}$ and $16 \mathrm{mmHg}$, respectively.

The slit-lamp and anterior segment examination of the left eye showed cortical cataract and tortuous neovascularization at the papillary margin of the iris; gonioscopy revealed rubeosis iridis (Figure 1A,B). A fundus examination of the right and left eyes showed mild non-proliferative diabetic retinopathy (NPDR) (Figure 1C,D). An optical coherence tomography (OCT) (Spectralis OCT; Heidelberg Engineering Inc., Heidelberg, Germany) examination showed no abnormal findings such as macular edema or nerve fiber layer defect in the $\mathrm{ONH}$ and the macular region (Figure 1E-H).

We measured MBR and BOS in the ONH tissue and vessel, and the choroid of the macular region using LSFG. We set the measurement circle at the center of the $\mathrm{ONH}$ and the macula in both the right and left eyes at the baseline visit while comparing the fundus photographs and the LSFG color composite map images (Figure 2A-D). Baseline MBRs in the ONH tissue, the ONH vessel, and the choroid in the left and right eyes were 7.5/13.4, 15.0/58.1, and 6.7/15.6, respectively. Baseline BOSs in the entire $\mathrm{ONH}$ and in the choroid in the left and right eyes was 47.1/65.4 and 47.2/ 65.6, respectively.

Subsequently, we performed FA and ICGA to examine the time of the choroidal flush, the arm-to-retina, and the retinal circulation. Although the FA findings showed no retinal non-perfusion areas, the time of the choroidal flush was $20 \mathrm{~s}$ (Figure 2E), the arm-to-retina was $26 \mathrm{~s}$ (Figure 2F), and the retinal circulation was $22 \mathrm{~s}$, suggesting a delay. Findings from the FA examination of the anterior segment in the left eye showed massive fluorescein leakage from the rubeosis iridis (Figure 2G). ICG findings also revealed a delay in the arm-to-choroid time of $19 \mathrm{~s}$ after the injection (Figure 2H).

In order to evaluate the ICA stenosis, a carotid ultrasound was performed, and it showed $76 \%$ stenosis of the left ICA. The laboratory blood test findings showed that the hemoglobin A1c $(\mathrm{HbA1c})$ was $9.5 \%$ and the total cholesterol level was $285 \mathrm{mg} / \mathrm{dl}$, suggesting that they were elevated. We referred the patient to the department of neurosurgery and internal medicine, where it was determined that ICA stenting was not necessary for the stenosis.

The patient was diagnosed with OIS associated with the left ICA stenosis based on the above mentioned clinical findings and thus treatment was initiated. The regimen entailed one injection of bevacizumab (IVB), administration of Rho-associated kinase inhibitor eye drops ( $0.4 \%$ ripasudil), 
acetazolamide (750 $\mathrm{mg}$ per day) for three days, metformin tablets (500 $\mathrm{mg}$ per day), and combination tablets of low-dose aspirin (100 mg) with lansoprazole (15 mg).

The time course of MBR and BOS in each vascular bed in the affected eye is shown in Table 1.
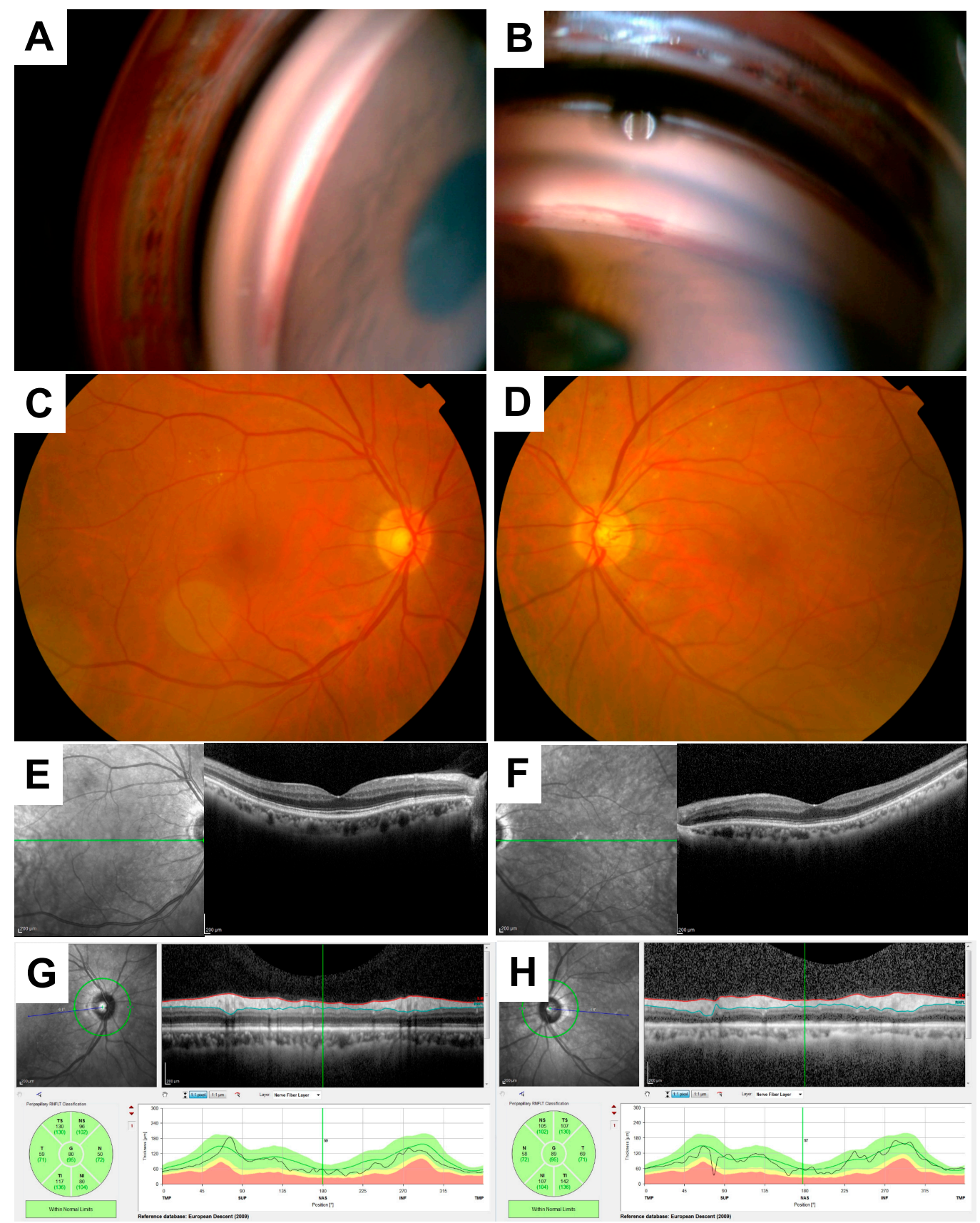

Figure 1. Gonioscopy, color fundus photography, and optical coherence tomography findings at the baseline visit. A gonioscopy photo of the left eye (A) and rubeosis iridis (B). Color fundus photography showed that the right (C) and left (D) eyes were normal. Optical coherence tomography (OCT) findings of the right (E) and the left (F) eyes showed no abnormal findings in the macular region. OCT findings of the right $(\mathbf{G})$ and the left $(\mathbf{H})$ eyes also showed normal finding. 

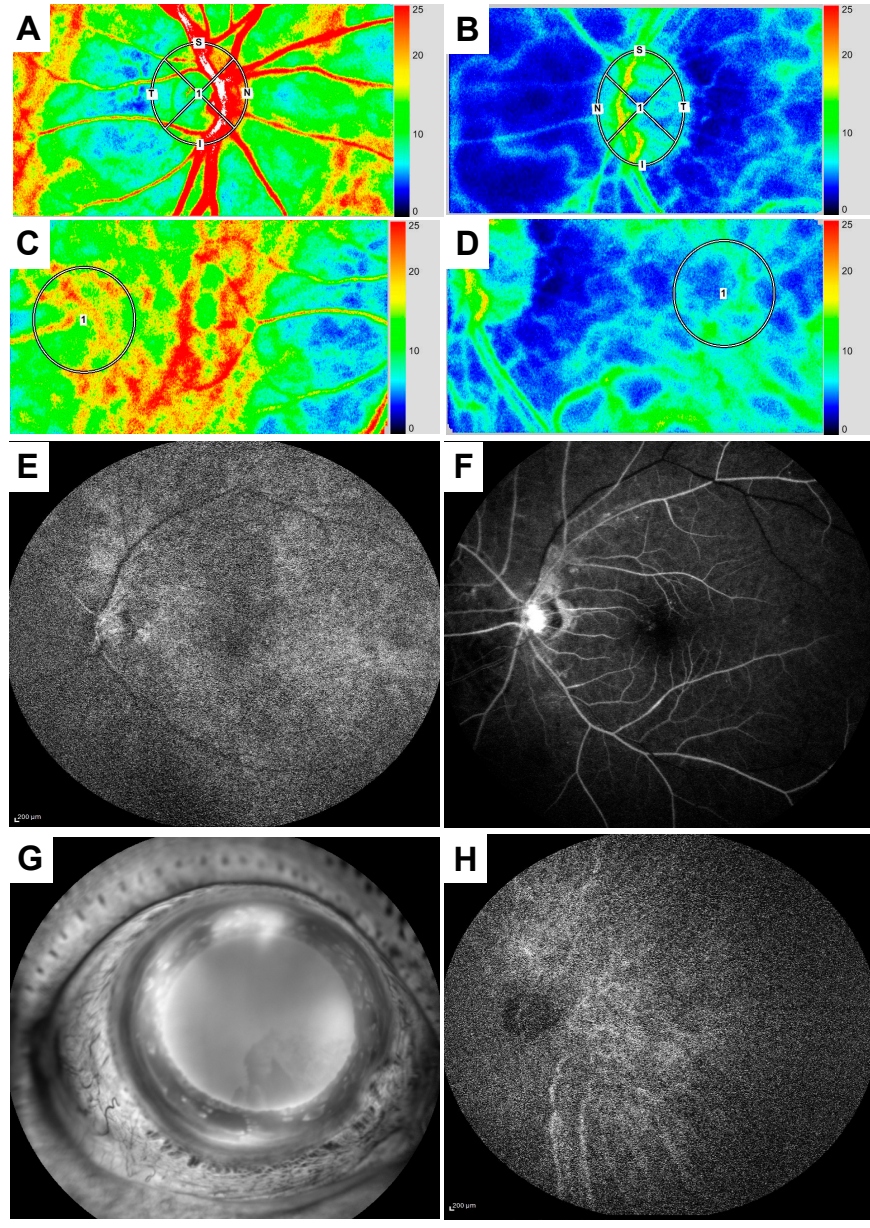

Figure 2. Laser speckle flowgraphy, fluorescein, and indocyanine green angiography findings from the baseline visit. Laser speckle flowgraphy (LSFG) findings in the optic nerve head (ONH) of the right (A) and left (B) eyes. LSFG findings in the macular of the right (C) and left (D) eyes. Fluorescein angiography (FA) findings in the left eye showed the prolonged times for the following: the choroidal flush was $20 \mathrm{~s}$ (E), the arm-to-retina was $26 \mathrm{~s}$ (F), and retinal circulation was $22 \mathrm{~s}$. FA findings of the anterior segment in the left eye showed massive fluorescein leakage from the rubeosis iridis (G). ICGA findings also revealed the delay of the arm-to-choroid circulation time which was $19 \mathrm{~s}(\mathbf{H})$.

Figure 3 shows the time course for the LSFG color composite map of the affected eye.

Table 1. Time course of mean blur rate and blowout score in the optic nerve head and choroid in the left eye. MBR; mean blur rate, $\mathrm{AU}$; arbitrary units, $\mathrm{ONH}$; optic nerve head, BOS; blowout score.

\begin{tabular}{cccccc}
\hline & $\begin{array}{c}\text { MBR in the } \\
\text { ONH } \\
\text { Vessel (AU) }\end{array}$ & $\begin{array}{c}\text { MBR in the } \\
\text { ONH } \\
\text { Tissue (AU) }\end{array}$ & $\begin{array}{c}\text { MBR in the Choroid } \\
\text { (AU) }\end{array}$ & $\begin{array}{c}\text { BOS in the Entire } \\
\text { ONH (AU) }\end{array}$ & $\begin{array}{c}\text { BOS in the } \\
\text { Choroid (AU) }\end{array}$ \\
\hline Baseline & 15.0 & 7.5 & 6.7 & 47.1 & 47.2 \\
\hline 4 days & 15.4 & 7.7 & 5.1 & 58.2 & 49.0 \\
\hline 2 weeks & 19.5 & 8.4 & 8.7 & 69.2 & 61.0 \\
\hline 3 months & 20.4 & 8.5 & 9.0 & 74.3 & 65.4 \\
\hline 5 months & 22.2 & 8.4 & 8.7 & 67.0 & 64.2 \\
\hline
\end{tabular}




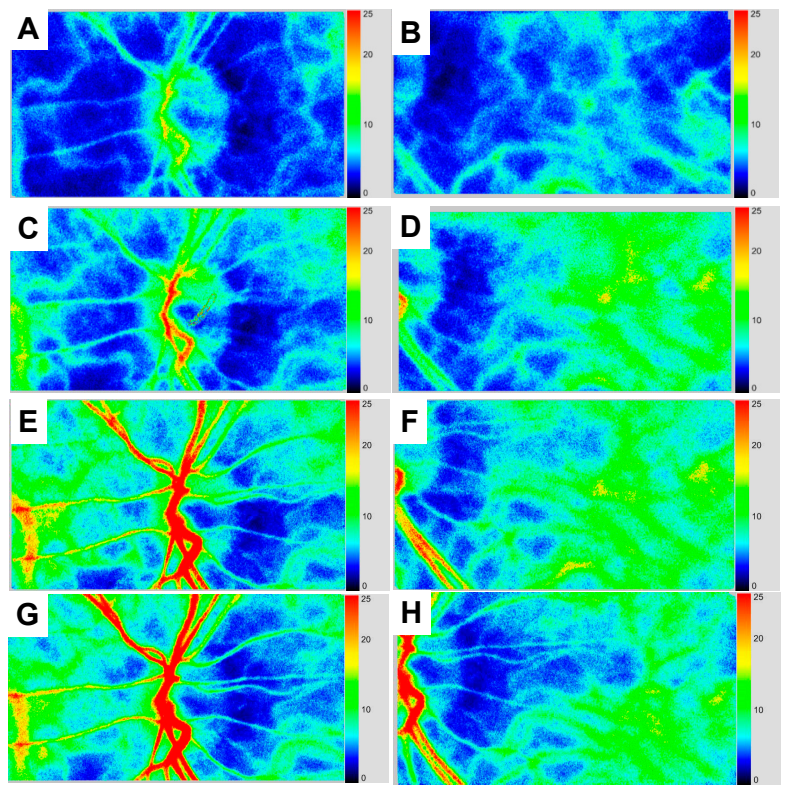

Figure 3. The time course exhibited by the laser speckle flowgraphy color composite map. LSFG images in the optic nerve head and the choroid of the left eye at 4 days (A,B), 2 weeks (C,D), 3 months $(\mathbf{E}, \mathbf{F})$, and 5 months $(\mathbf{G}, \mathbf{H})$ after the baseline visit. The LSFG images showed that warm colors increased over time. The Mean blur rate and blowout scores in each vascular bed also increased after treatment.

Four days after the baseline visit, anterior segment examination and gonioscopy showed reduced rubeosis iridis, and the IOP in the affected eye decreased to $41 \mathrm{mmHg}$. However, the LSFG findings showed no improvement in blood flow in each ocular vascular bed when compared to the baseline visit (Figure 3A,B).

Two weeks after the baseline visit, the IOP in the affected eye reduced to $15 \mathrm{mmHg}$, and the decimal BCVA in the left eye improved to 0.6 without visual field defect based on the Goldman visual field test. Gonioscopy showed the near disappearance of the rubeosis iridis. LSFG findings in the left eye indicated that warm colors were increased compared to the findings from the baseline visit (Figure 3C,D).

Three months after the baseline visit, the left decimal BCVA and IOP were 0.6 and $21 \mathrm{mmHg}$ using $0.4 \%$ ripasudil, respectively. The anterior segment examination of the left eye and gonioscopy showed no rubeosis iridis (Figure $4 \mathrm{~A}, \mathrm{~B}$ ), and the LSFG results demonstrated that warm colors were more prevalent when compared to that from the baseline visit. MBR in the ONH tissue and vessel increased from 15.0 to 20.4 and 7.5 to 8.5 , respectively. Choroidal blood flow also increased from 6.7 to 9.0 (Table 1, Figure 3E,F). In addition to MBR, BOS in the entire ONH and in the choroid also significantly increased from 47.1 to 74.3 and 47.2 to 65.4 , respectively. Figure 5 shows the changes in pulse waveform for the entire $\mathrm{ONH}$ and choroid between the 3 month and baseline visit; it showed less fluctuation in the $\mathrm{ONH}$ and choroidal blood flow 3 months after treatment initiation. We thus repeated the FA and ICGA; the FA findings for the left eye showed no delays. The choroidal flush occurred in $16 \mathrm{~s}$ (Figure 4C), the arm-to-retina time was $18 \mathrm{~s}$ (Figure 4D), and the retinal circulation time was $10 \mathrm{~s}$. There was no leakage in the left anterior segment (Figure 4E). The ICGA findings at $19 \mathrm{~s}$ after the injection (Figure $4 \mathrm{~F}$ ) show improvements in choroidal circulation when compared to that from the baseline visit.

Five months after the baseline visit (the last visit), the IOP in the affected eye was $18 \mathrm{mmHg}$ and the BCVA in the affected eye was 0.6 without any ophthalmic treatment. Laboratory blood tests showed reductions in the $\mathrm{HbA} 1 \mathrm{c}(7.3 \%)$ and the cholesterol $(181 \mathrm{mmg} / \mathrm{dl})$ levels. LSFG findings demonstrated sufficient blood flow and higher BOS in each vascular bed compared with that at the last visit (Table 1, 
Figure 3G,H). During the follow-up periods, the patients did not receive the retinal photocoagulation and revascularization surgery.
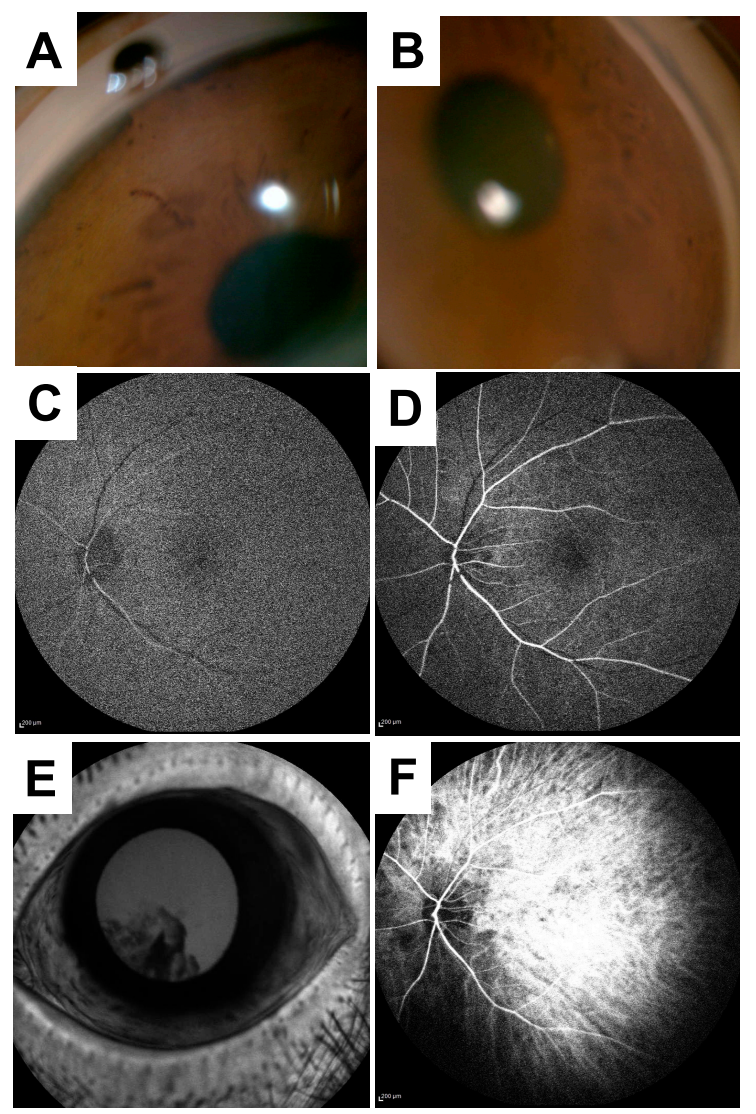

Figure 4. Gonioscopy, fluorescein, and indocyanine green angiography findings 3 months after the baseline visit. A gonioscopy photo of the left eye (A) and showing no rubeosis iridis (B). Fluorescein angiography (FA) of the left eye shows no delays in the following: the choroidal flush was $16 \mathrm{~s}$ (C), the arm-to-retina time was $18 \mathrm{~s}(\mathbf{D})$, and the retinal circulation time was $10 \mathrm{~s}$. There was no leakage in the left anterior segment (E). An indocyanine green angiography (ICGA) at the early phase was $19 \mathrm{~s}$ (F).

\section{A Baseline visit (IOP: 50mmHg) B 3 months (IOP: $21 \mathrm{mmHg}$ )}
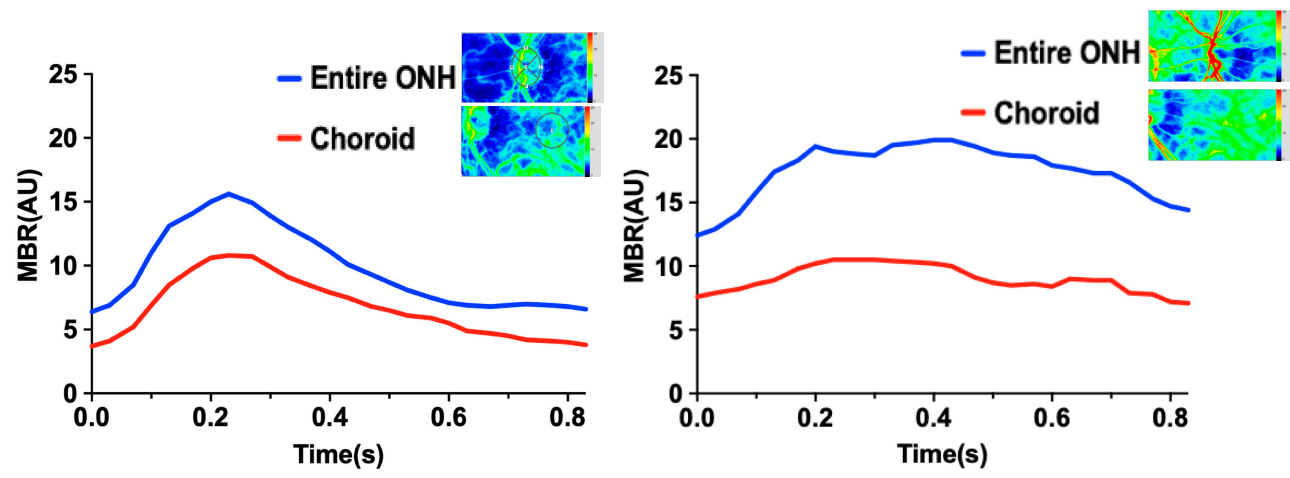

Figure 5. Changes in the pulse waveform in the entire optic nerve head and the choroid at baseline and 3 months after treatment. Pulse waveform in the entire optic nerve head (ONH) and the choroid at baseline. Intraocular pressure (IOP) was $50 \mathrm{mmHg}(\mathrm{A})$. Pulse waveform in the entire $\mathrm{ONH}$ and the choroid 3 months after treatment. IOP was $21 \mathrm{mmHg}(\mathbf{B})$. Blue color indicates the entire $\mathrm{ONH}$, and red color indicates the choroid. 
In the current case, we measured the IOP and patient's systolic and diastolic blood pressure (SBP and DBP) for calculation of the mean blood pressure (MBP) and OPP at every visit [18]. OPPs at the baseline, 2 weeks, 3 month, and 5 month visits in the left and right eyes were 31.3 and $65.3 \mathrm{mmHg}, 65.7$ and $64.7 \mathrm{mmHg}, 61.6$ and $67.6 \mathrm{mmHg}$ and 60.8 and $61.8 \mathrm{mmHg}$, respectively.

Subject gave informed consent for inclusion before they participated in the study. The study was conducted in accordance with the Declaration of Helsinki, and the protocol was approved by the Ethics Committee of Toho University Sakura Medical Center (number: 2015056).

\section{Discussion}

In the present case, we revealed the time course of the blood flow and pulse waveform in the $\mathrm{ONH}$ and choroid along with IOP reduction using LSFG before and after the treatment in OIS. To our knowledge, this is the first time this has been completed.

At the baseline visit, the ocular blood flow in the ONH tissue and vessel area, and the choroid of the left eye was decreased compared with that in the fellow eye. Additionally, the degree of ICA stenosis was $76 \%$. This finding is similar to that from a previous study in which the degree of the ICA stenosis and the ratio of the affected to the fellow eye was shown to be inversely correlated [17]. In the present case we found a higher level of $\mathrm{HbA} 1 \mathrm{c}$ and IOP $(50 \mathrm{mmHg})$ caused by rubeosis iridis. It was previously demonstrated that type 2 diabetes [19], hypertension, and hyperlipidemia [20] are associated with impaired $\mathrm{ONH}$ blood flow autoregulation in both vascular and tissue areas in response to elevated IOP. Additionally, the degree of autoregulation in the $\mathrm{ONH}$ was negatively correlated with the $\mathrm{HbA1c}$ level. Akahori et al. reported that there was a significant correlation between the percent reduction for the OPP and the choroidal MBR during the elevation of IOP by $30 \mathrm{mmHg}$, even among healthy subjects [21]. Based on the above findings, it is understandable that the decreased blood flow in each vascular bed is mainly associated with impaired $\mathrm{ONH}$ and choroidal blood flow autoregulation due to the decreased OPP in addition to the ICA stenosis.

The current case showed that MBR in each vascular bed gradually increased along with reduced IOP compared to that at baseline. After treatment for rubeosis iridis using the IVB injection and $0.4 \%$ ripasudil ophthalmic solution, OPP was significantly increased twofold by a reduction in IOP. Riva et al. reported that there is a linear relationship between choroidal blood flow and OPP in healthy subjects [22]. Another study also demonstrated that the percent change in the OPP and MBR showed positive linear correlations in the choroid and the $\mathrm{ONH}$ [23]. In this case, the patient was given an antiplatelet tablet and ripasudil eye drops. The antiplatelet is known to increase pulsatile ocular blood flow among those with diabetic retinopathy [24]; ripasudil has also been reported to increase $\mathrm{ONH}$ blood flow in the eyes of normal rats $[25,26]$. The level of the HbA1C and cholesterol reduced several months after the initial visit. The pulsatile ocular blood flow is influenced by changes in plasma glucose concentrations in Type II diabetes mellitus [27]. In light of these findings and that incremental OPP due to decrement IOP, the improvement of the general condition and these administrative treatments might improve $\mathrm{ONH}$ and choroidal blood flow.

In addition to MBR, the present case showed lower BOS, which means a greater fluctuation in blood flow, in each vascular bed at the baseline visit. The BOS gradually increased after the treatment over the follow-up period. The graph of the pulse waveforms in the entire $\mathrm{ONH}$ and the choroid (Figure 4) showed less fluctuation in blood flow 3 months after treatment, compared with that at the baseline visit.

A previous study found that BOS was decreased among those with a high IOP [23]. In the current case, ripasudil was reported to suppress the activity of rho/rock kinase two and further increased the endothelial nitric oxide synthase activity [28], which is crucial for nitric oxide (NO)-mediated vasodilation of vessels after arterial occlusion [29]. Additionally, metformin improved the endothelial function and reduces blood pressure via the up-regulation of NO in the diabetic animal model [30]. Considering the above and the fact that BOS is an index of the blood flow that is maintained between heartbeats, the lower BOS of the eye with the OIS suggests that ocular circulation was unstable 
and insufficient when the IOP was elevated. Besides, the increase in BOS might be related to the improvements in vasodilation due to these administrative treatments.

Lastly, in the current case there were increases in MBR and BOS in each vascular bed as visualized using LSFG, and there was a shortened circulation time for the choroidal and the retina obtained using FA and ICGA. Nagasato et al. reported that MBR was significantly correlated with the arteriovenous passage time obtained by FA [31]. From the above findings, LSFG might have the potential to assess these circulation times instead of FA and ICG. However, further studies are needed to evaluate whether the changes in these circulation times using FA and ICGA are associated with those in the MBR and those obtained by the LSFG displayed using the pulse wave.

In conclusion, the current case demonstrated increased blood flow and decreased fluctuation of blood flow in the ONH and choroid along with IOP reduction. The LSFG technique is useful to non-invasively assess the time course in ocular circulation and pulse waveform in OIS.

Author Contributions: Conceptualization: R.H.; investigation: R.Y., R.H., H.M., and M.S.; writing一original draft preparation: R.Y. and R.H.; writing-review and editing: R.H. and T.M. All authors have read and agreed to the publication of the final version of this manuscript.

Funding: This research received no external funding.

Conflicts of Interest: The authors declare no conflicts of interest.

\section{References}

1. Mendrinos, E.; Machinis, T.G.; Pournaras, C.J. Ocular ischemic syndrome. Surv. Ophthalmol. 2010, 55, 2-34. [CrossRef] [PubMed]

2. Hayreh, S.S. Blood supply of the optic nerve head and its role in optic atrophy, glaucoma, and oedema of the optic disc. Br. J. Ophthalmol. 1969, 53, 721-748. [CrossRef] [PubMed]

3. Ishii, M.; Hayashi, M.; Yagi, F.; Sato, K.; Tomita, G.; Iwabuchi, S. Relationship between the Direction of Ophthalmic Artery Blood Flow and Ocular Microcirculation before and after Carotid Artery Stenting. J. Ophthalmol. 2016, 2016, 2530914. [CrossRef] [PubMed]

4. Brown, G.C.; Magargal, L.E. The ocular ischemic syndrome. Clinical, fluorescein angiographic and carotid angiographic features. Int. Ophthalmol. 1988, 11, 239-251. [CrossRef]

5. Kim, Y.H.; Sung, M.S.; Park, S.W. Clinical Features of Ocular Ischemic Syndrome and Risk Factors for Neovascular Glaucoma. Korean J. Ophthalmol. 2017, 31, 343-350. [CrossRef] [PubMed]

6. Hayreh, S.S.; Zimmerman, M.B. Ocular arterial occlusive disorders and carotid artery disease. Ophthalmol. Retin. 2017, 1, 12-18. [CrossRef]

7. Utsugi, N.; Takahashi, K.; Kishi, S. Choroidal vascular occlusion in internal carotid artery obstruction. Retina 2004, 24, 915-919. [CrossRef]

8. Obana, A.; Miki, T.; Hayashi, K.; Takeda, M.; Kawamura, A.; Mutoh, T.; Harino, S.; Fukushima, I.; Komatsu, H.; Takaku, Y.; et al. Survey of complications of indocyanine green angiography in Japan. Am. J. Ophthalmol. 1994, 118, 749-753. [CrossRef]

9. Yannuzzi, L.A.; Rohrer, K.T.; Tindel, L.J.; Sobel, R.S.; Costanza, M.A.; Shields, W.; Zang, E. Fluorescein angiography complication survey. Ophthalmology 1986, 93, 611-617. [CrossRef]

10. Aizawa, N.; Nitta, F.; Kunikata, H.; Sugiyama, T.; Ikeda, T.; Araie, M.; Nakazawa, T. Laser speckle and hydrogen gas clearance measurements of optic nerve circulation in albino and pigmented rabbits with or without optic disc atrophy. Investig. Ophthalmol. Vis. Sci. 2014, 55, 7991-7996. [CrossRef]

11. Hashimoto, R.; Sugiyama, T.; Ubuka, M.; Maeno, T. Autoregulation of Optic Nerve Head Blood Flow Induced by Elevated Intraocular Pressure during Vitreous Surgery. Curr. Eye Res. 2016, 1-4. [CrossRef] [PubMed]

12. Matsumoto, M.; Suzuma, K.; Fukazawa, Y.; Yamada, Y.; Tsuiki, E.; Fujikawa, A.; Kitaoka, T. Retinal blood flow levels measured by laser speckle flowgraphy in patients who received intravitreal bevacizumab injection for macular edema secondary to central retinal vein occlusion. Retin. Cases Brief. Rep. 2014, 8, 60-66. [CrossRef] [PubMed]

13. Iwase, T.; Ra, E.; Yamamoto, K.; Kaneko, H.; Ito, Y.; Terasaki, H. Differences of Retinal Blood Flow Between Arteries and Veins Determined by Laser Speckle Flowgraphy in Healthy Subjects. Medicine 2015, 94, e1256. [CrossRef] [PubMed] 
14. Hashimoto, R.; Hirota, A.; Maeno, T. Choroidal blood flow impairment demonstrated using laser speckle flowgraphy in a case of commotio retinae. Am. J. Ophthalmol. Case Rep. 2016, 4, 30-34. [CrossRef]

15. Saito, W.; Hashimoto, Y.; Hirooka, K.; Ishida, S. Changes in choroidal blood flow velocity in patients diagnosed with central serous chorioretinopathy during follow-up for pachychoroid pigment epitheliopathy. Am. J. Ophthalmol. Case Rep. 2020, 18, 100651. [CrossRef]

16. Sugiyama, T. Basic Technology and Clinical Applications of the Updated Model of Laser Speckle Flowgraphy to Ocular Diseases. Photonics 2014, 1, 220-234. [CrossRef]

17. Shinohara, Y.; Kashima, T.; Akiyama, H.; Shimoda, Y.; Li, D.; Kishi, S. Evaluation of Fundus Blood Flow in Normal Individuals and Patients with Internal Carotid Artery Obstruction Using Laser Speckle Flowgraphy. PLOS ONE 2017, 12, e0169596. [CrossRef]

18. Costa, V.P.; Harris, A.; Anderson, D.; Stodtmeister, R.; Cremasco, F.; Kergoat, H.; Lovasik, J.; Stalmans, I.; Zeitz, O.; Lanzl, I.; et al. Ocular perfusion pressure in glaucoma. Acta Ophthalmol. 2014, 92, e252-e266. [CrossRef]

19. Hashimoto, R.; Sugiyama, T.; Masahara, H.; Sakamoto, M.; Ubuka, M.; Maeno, T. Impaired Autoregulation of Blood Flow at the Optic Nerve Head during Vitrectomy in Patients with Type 2 Diabetes. Am. J. Ophthalmol. 2017, 181, 125-133. [CrossRef]

20. Hashimoto, R.; Sugiyama, T.; Ubuka, M.; Maeno, T. Impairment of autoregulation of optic nerve head blood flow during vitreous surgery in patients with hypertension and hyperlipidemia. Graefes Arch. Clin. Exp. Ophthalmol. 2017, 255, 2227-2235. [CrossRef]

21. Akahori, T.; Iwase, T.; Yamamoto, K.; Ra, E.; Terasaki, H. Changes in Choroidal Blood Flow and Morphology in Response to Increase in Intraocular Pressure. Invest. Ophthalmol. Vis. Sci. 2017, 58, 5076-5085. [CrossRef]

22. Riva, C.E.; Titze, P.; Hero, M.; Petrig, B.L. Effect of acute decreases of perfusion pressure on choroidal blood flow in humans. Investig. Ophthalmol. Vis. Sci. 1997, 38, 1752-1760.

23. Kiyota, N.; Shiga, Y.; Ichinohasama, K.; Yasuda, M.; Aizawa, N.; Omodaka, K.; Honda, N.; Kunikata, H.; Nakazawa, T. The Impact of Intraocular Pressure Elevation on Optic Nerve Head and Choroidal Blood Flow. Investig. Ophthalmol. Vis. Sci. 2018, 59, 3488-3496. [CrossRef] [PubMed]

24. Hwang, D.J.; Shin, J.Y.; Yu, H.G. Oral Administration of Cilostazol Increases Ocular Blood Flow in Patients with Diabetic Retinopathy. Korean J. Ophthalmol. 2017, 31, 123-131. [CrossRef] [PubMed]

25. Wada, Y.; Higashide, T.; Nagata, A.; Sugiyama, K. Effects of ripasudil, a rho kinase inhibitor, on blood flow in the optic nerve head of normal rats. Graefes Arch. Clin. Exp. Ophthalmol. 2019, 257, 303-311. [CrossRef] [PubMed]

26. Kohmoto, R.; Sugiyama, T.; Kojima, S.; Ueki, M.; Ikeda, T. Optic Nerve Blood Flow Change Induced Ripasudil Added to Prostaglandin Analogues in Primary Open Angle Glaucoma. EC Ophthalmol. 2017, 4, 640-647.

27. Perrott, R.L.; North, R.V.; Drasdo, N.; Ahmed, K.A.; Owens, D.R. The influence of plasma glucose upon pulsatile ocular blood flow in subjects with type II diabetes mellitus. Diabetologia 2001, 44, 700-705. [CrossRef]

28. Mees, B.; Wagner, S.; Ninci, E.; Tribulova, S.; Martin, S.; van Haperen, R.; Kostin, S.; Heil, M.; de Crom, R.; Schaper, W. Endothelial nitric oxide synthase activity is essential for vasodilation during blood flow recovery but not for arteriogenesis. Arterioscler. Thromb. Vasc. Biol. 2007, 27, 1926-1933. [CrossRef]

29. Yang, J.; Ruan, F.; Zheng, Z. Ripasudil Attenuates Lipopolysaccharide (LPS)-Mediated Apoptosis and Inflammation in Pulmonary Microvascular Endothelial Cells via ROCK2/eNOS Signaling. Med. Sci. Monit. 2018, 24, 3212-3219. [CrossRef]

30. Hamidi Shishavan, M.; Henning, R.H.; van Buiten, A.; Goris, M.; Deelman, L.E.; Buikema, H. Metformin Improves Endothelial Function and Reduces Blood Pressure in Diabetic Spontaneously Hypertensive Rats Independent from Glycemia Control: Comparison to Vildagliptin. Sci. Rep. 2017, 7, 10975. [CrossRef]

31. Nagasato, D.; Mitamura, Y.; Semba, K.; Akaiwa, K.; Nagasawa, T.; Yoshizumi, Y.; Tabuchi, H.; Kiuchi, Y. Correlation between optic nerve head circulation and visual function before and after anti-VEGF therapy for central retinal vein occlusion: Prospective, interventional case series. BMC Ophthalmol. 2016, 16, 36. [CrossRef] [PubMed]

(C) 2020 by the authors. Licensee MDPI, Basel, Switzerland. This article is an open access article distributed under the terms and conditions of the Creative Commons Attribution (CC BY) license (http://creativecommons.org/licenses/by/4.0/). 